\title{
The Effect of Teacher Expectation to Students' Intrinsic Motivation
}

\author{
Chuantong Shan ${ }^{1, *}$

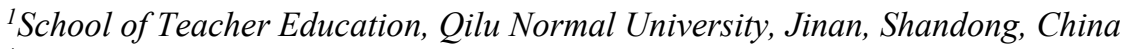 \\ ${ }^{*}$ Corresponding author.Email: SctTengzhou@st.btbu.edu.cn
}

\begin{abstract}
The question of how teacher expectations affect students is still unclear, especially the impact on students' intrinsic motivation. This paper explored the question by discussing the effects of teacher expectation on students' intrinsic motivation and how it affects students. Reviewing previous studies found that teacher expectations were positively but moderately associated with students' intrinsic motivation. Teacher expectation effect students firstly by Good and Brophu's teacher expectation process model. Secondly, based on Rosenthal's four-factor model, teacher expectation and be showed by classroom atmosphere, teaching feedback, teaching input and classroom output, these factors will affect students' intrinsic motivation and academic performance. Thirdly, a teacher can affect students' academic motivation by a series of psychological mediation. Finally, teacher expectation can affect students' sense of control and self-concept, attribution, and self-efficiency are three main factors. Future research can explore teacher expectations on different ages and gender to refine the extent of influence. Also, because of the development of distance education, researchers were also able to explore whether students' intrinsic motivation changed because of online teaching.
\end{abstract}

Keywords: Teacher expectation, Students' intrinsic motivation.

\section{INTRODUCTION}

This paper talked about the effect of perceived teachers' expectations on students' intrinsic motivation. There is a lot of research exploring teacher expectations after Rosenthal and Jacobson's research did the research called Pygmalion in the classroom [1]. The experiment had a big effect on that time, and there also have many distributions about the process and the result of the research. After that, many educational psychologists started to refine the experiment and extend the range of the research. Hoge summarized the research of teacher expectation in the last 16 years, pointed the problems of Rosenthal and Jacobson's research, and gave the prospections of future research. The problem was as follows: the used experiments lack direct evidence of the validity of teacher expectation and manipulation. Then, it leads to the doubt on expectancy manipulation when represented in researches [2]. Then some psychologists refined the research pf teacher expectation to some aspects, like the effect of students' perceptions of differential teacher treatment, it can be a moderate to teacher expectation effect [3]. The research of West and Anderson present the major elements of teacher expectancy. They also propose many competing hypotheses. Reviewed research related to the expected hypothesis and alternative hypothesis [4]. Then research increased to research the relation of teacher expectation and student achievement. Sam did the test of "Teacher expectation and student achievement" (TEST) [5]. The original name was called "Equal Opportunity in the classroom" (EOC). Chang also did a case study of the "Pygmalion Effect", The research shows "in the educational domain, it is not always the case that "you get what you expect [6]. There are multiple factors besides teacher expectation influence students' motivation, enthusiasm and achievement. The case study expanded the research category of motivation, and it also shows the validity of the "Pygmalion Effect" in contemporary society. With the deeper exploration of teacher expectation, some researchers control the traits to change teacher expectation and composed a model of high expectation teachers. Then, researchers measured the effect of teacher expectation on students' mathematics and reading achievement and concluded that teacher expectations have different effects on specific subjects [7]. 
Rosenthal's four-factor model can show the differential of teacher expectation: Classroom atmosphere, teaching feedback, teaching input, and classroom output. Also, verbal and nonverbal behaviours can also be approaches for teachers to show their different expectations. Then, students' perceived expectations will have effects on their academic performance [8]. On the other side, inaccurate teacher expectations are associated with students' greater achievement in reading and mathematics. Also, the feedback of teachers varied significantly with the inaccurate teacher expectations, but it did not substantially mediate teacher expectancy effects [9]. With the development of technology, research of teacher expectation and students' intrinsic motivation under the background of online teaching, and students' intrinsic motivation improved under the game-based environment [10]. The effect of teacher expectation on students' intrinsic motivation is important for developing teacher techniques, and balancing the class relationship contributes to composing a fair teaching environment. Also, the research can help teachers master different students' situation and take the correct methods, making most of the students acquire the best academic performance and healthy psychological development

In the past research, the effect extent of teacher expectation on students' intrinsic motivation has changed, and more traits can influence students' motivation. However, during the research, the control of teacher expectation is not easy to control because there are many intervention factors from teachers and students. Moreover, the researches still lack systematic explore about different age and gender's effect for teacher expectation. Therefore, this research refined the effect of teacher expectation on students' intrinsic motivation. On this basis, the paper also explored how teacher expectation caused an effect on students. For the first part of the research, the paper researched the perceived teacher expectation. Then, it introduced the conception of teacher expectation and some specific behaviours showing teacher expectation. It also showed the ways to measure students' intrinsic motivation Last, it showed the effect of teacher expectation on students. For the second part mainly talked about the intrinsic motivation of students. And we talked about the research about the conception of students' intrinsic motivation and its influence on students' academic performance in this part. The next part is the effect of teacher expectation and the ways of it effect students' intrinsic motivation. The last part talked the barrier of existing researches, and gave some directions for future research.

\section{PERCEIVED TEACHER EXPECTATION}

\subsection{The conception of teacher expectation and the performance}

Researchers in the fields of education have not studied the expectancy effect until Rosenthal and Jacobson [1]. They experimented, Pygmalion in the classroom, and the aim of the research is the degree of teacher expectation can affect student achievement. Based on the research, Rosenthal and Jacobson concluded that teachers' belief on the students' potential caused a self-fulling prophecy. Teachers confirmed that teacher expectation would promote some children's development on intelligence development [1]. Although teacher expectation is the main variable on the research, Rosenthal and Jacobson did not directly discuss the conception of teacher expectation [1]. Since 1968, many researchers have defined teacher expectation: Brophy and Good gave the under definition: "By "teacher expectations' we mean inferences that teachers make about the present and future academic achievement and general classroom behaviour of their students". They also gave a further definition: "Expectations are primarily cognitive phenomena, inferential judgments about probable future achievement and behaviour based upon the student's past record and his present achievement and behaviour" [11]. The other investigator also gave the definition of the conception of teacher expectation. In 1984, Cooper divided the conception of teacher expectation into three categories: estimates of presentability or achievement (it concerns to students' general competencies, or the extent of them to perform in particular achievement domains), expected improvement (the prediction of teachers on students' academic progress in a specified period), and natural discrepancies between teachers and tests (the difference between students' present performance and teachers' inference) [12].

Researchers analysed teacher expectation from different aspects, and the performance of teacher expectation can be seen in teaching practice and application. Based on Rosenthal's four-factor model, teachers' expectation can be shown on classroom atmosphere (teachers can create a relatively relaxed atmosphere for high expectation students by verbal or nonverbal approach), teaching feedback (teachers will provide more and more positively teaching feedback to high expectation students than low expectation students), teaching input (teachers will provide more study materials to high expectation students) and classroom output(teachers will give high expectation students to output information than other students) [8]. On the other hand, the expression of teachers' expectations can be shown on two ways: verbal and nonverbal behaviour. Hankins defines verbal behaviour as" the attitude emitted through the spoken language 
[13]." As Asghar and Arif said: "nonverbal communication is the unspoken communication that goes on in every face-to-face encounter with another human being. It tells un the true feelings towards us and how well are our words being received [14]." Teachers will not give direct verbal reactions to low- expectation students to avoid discouraging students' enthusiasm on the teaching processing. Therefore, compared to these two ways, non-verbal is the more meaningful way to express expectations. The non-verbal behaviours are continuous and real, and in the teaching process, teachers will continue to express their personal emotions by eye contact, expression, and body movement. Therefore, students can get the different expectations and attitudes of teachers [8].

As the Chinese researcher Haiyan and Minqiang, they conducted the result of Rosenthal and Harris, subdivision 31 behaviours of teachers to express their expectation: (1) active atmosphere; (2) smile; (3) eye contact or gaze; (4) physically inclined students; (5) nod; (6) contact; (7) hand gesture; (8) body distance between teachers and students; (9) speed of speaking; (10) teachers' verbal or non-verbal encouragement; (11) teachers' recognizes the students' opinions; (12) indirect influence; (13) compliment; (14) reinforce promptly after answering the questions correctly; (15) input; (16) the number of questions; (17) persistence; (18) number of interactions; (19) interaction time; (20) contacts not related to teaching; (21) routine contact; (22) tendency towards teaching work; (23) waiting time; (24) negative atmosphere; (25) criticism; (26) ignoring students; (27) giving orders; (28) teaching; (29) direct influence; (30) behaviours unrelated to teaching; (31) criticism after a student's wrong reaction [15]. The conclusion is also on the basis of Rosenthal's four-factor model and analysed it into more specific behaviours.

\subsection{The measurement of perceived teacher expectation}

There are many ways to measure perceived teacher expectations. Robert divided the measures into three categories: a global estimate of pupil's academic potential, global ratings of expected task performance and multivariate indices of expectancy [2]. These measurement ways have multiple variables. To measure students' perceived expectations, researchers controlled the traits of teacher expectation. Teachers $(\mathrm{N}=84)$ were randomly assigned to intervention or control groups. Teachers in the intervention group attended four workshops. At each seminar, the teachers in groups all planned to change methods to imitate the behaviours of high expectation teacher and introduce to the class. Researchers also visited teachers on three further occasions to ensure the fidelity of the implementation. After the one-year longitudinal study, the mathematics grades of students in the class of the intervention group significantly improved [7].

\subsection{The effects of teacher expectations to students}

The differential of teacher expectation mainly has four ways to show, and students perceived expectation could affect their performance. The high teachers' expectations can contribute to the development of students. Teachers' expectations significantly impact students' sense of learning ability, academic achievement motivation, and academic performance [16]. A student mediation model of teacher expectation effects proposes that students get information about their abilities by observing teachers' differential treatment to low and high achieving students. Then, students will revise achievement expectations and subsequently perform themselves based on the perceived teacher expectation [3]. The other study of Brattesani, Weinstein and Marshall is that teacher expectation may predict students' academic achievement [3]. Also, some researchers analysed the relationship between teacher expectation and need-supportive teaching. On the basis of research results, they also conclude that teacher expectation affects students' intrinsic motivation, and their relation was fully mediated by students perceived teacher expectation [17].

Differential teacher expectations of different students can affect objective differences and hypotheses. The higher expectations students perceive, the better performances are demand [11]. On the basis of the performance that teachers affect students, researchers concluded that the results' teacher expectations cause different students' academic performance. With the increase of teachers' expectations, students' academic performance can get larger progress, whereas the distance between different expectations can be bigger [16]. Specific to academic performance, the different expectations can cause different academic performance. The mathematics scores of students who got high teacher expectations were significantly better than those who received low expectations [18]. There are some researchers who control the traits of teacher expectation got a model of the correlation between teacher expectation and students' mathematics score and Reading score. The empirical research results: the practiced high expectation teacher expectation increased students' mathematics scores over one year. Although the reading scores also improved, teachers acknowledged that it is easier to be high expectation in mathematics than in reading [7].

Also, some research also investigated the relationship between teacher expectation and adolescences' socio- emotional development. Nadya, Wuri and Mita researched the association of anxiety and 
teacher expectation among high school students, and revealed that teachers' expectation is not the risk factor of high school students' high anxiety in Jakarta [19]. The research expanded the category for the effect of teachers' expectations.

\section{THE INTRINSIC MOTIVATION OF STUDENTS}

\subsection{The conception of students' intrinsic motivation}

The difference between Intrinsic motivation and extrinsic motivation mainly on the source of rewards. Intrinsic motivation refers to adolescents' innate satisfaction and enjoyment from taking such kinds of initiatives [20]. Based on self-determination theory, intrinsic motivation is a natural tendency for humans to promote their integration into society through independent participation activities [20]. Therefore, it is mainly personally rewarding for you. In contrast, extrinsic motivation involves avoiding the punishment or getting rewards from outside, then doing some behaviours. Therefore, the difference between intrinsic motivation and extrinsic is the former comes from within, and the latter comes from outside.

Some researchers also defined intrinsic motivation as doing an activity for its inherent satisfactions rather than for some separable consequence. For example, when intrinsically motivated, a person is moved to act for the fun or challenge [20]. In contrast, the definition of extrinsic motivation is a construct that pertains, and all of the activities are done to attain some extra rewards. Thus, extrinsic motivation thus different from intrinsic motivation, which is doing an activity just for the enjoyment itself or its instrumental value [20].

\subsection{The influence of students' intrinsic motivation on academic performance}

In the past, most researchers measured students' academic on the basis of their academic grades, for example, the measurement of students' intrinsic motivation, on the experiment of Niehaus and Adelson, they used the Intrinsic and Extrinsic motivation scale (IEMS), and the scale has 30 items. The instrument of self-report was administrated to the students to assess motivational orientation [21]. The scale is a 5 Likert scale, with 2 subscales: the intrinsic motivation scale (17 items), and the extrinsic motivation scale (13 items). Participants need to the respondent the questions ranging from $0=$ not like me at all to $4=$ exactly like me. In this experiment, the researchers only used the subscale of the intrinsic scale, which has acceptable levels of internal reliability in Lepper, Corpus, and Iyengar's sample and in the present sample of Niehaus and Adelson [22]. During the research, academic performance was shown by GPA. The measurement of the result has controlled students' prior reading achievement. After a year's longitudinal study, the students who have higher intrinsic motivation at the beginning of the year have higher GPAs at the end of the year. In conclusion, the students who have higher intrinsic motivation have better academic performance and grades.

With the development of technology, more and more parents would let their children learn programs at an early age to cultivate their Computational Thinking. Teachers often make a game-based environment which used to develop their skills. Although children can get some skills, they still lack sufficient voluntariness to assess their intrinsic motivation, such as skills, the interest in learning, persistence in solving problems and behaviour in response to rewards. These aspects of intrinsic motivation will directly affect students' academic performance and achievement [10]. Therefore, the empirical research that MARÍA and ESTEFANÍA did by developed voluntary video games with basic computational concepts, the research based on intrinsic motivation, and the aim is early ages. Researchers collected and analyzed data using game learning analytical for 15 months. During the whole process, 4124 users played more than 28187 games. The analysis results show significant age and gender differences in relation to interests, skills, achievement, and progression through attempts. As a result conclude, intrinsic motivation has a positive correlation with learning, persistence, self-competence and self-efficiency. Also, the researchers said: "specific motivational styles directly affect achievement and academic performance, and these styles could be detected and developed through video games." Therefore, video games can affect students' academic intrinsic motivation, and they can as a tool helping students improve their academic performance [10]. Also, some researchers take influence of students' intrinsic motivation on the basis of e-learning environments. By the analyses, "the level of intrinsic motivation of open and distance education students is high in e-learning environments [23]."

\section{THE EFFECT OF TEACHERS' EXPECTATION TO STUDENTS' INTRINSIC MOTIVATION}

\subsection{The effects of perceived teacher expectation to students' intrinsic motivation}

Rosenthal's four-factor model can perform teacher expectations, these expectations lead teachers to treat higher- and lower-expectancy students differently, and students will revise achievement expectations and subsequently perform of themselves on the basis of their perceived teacher expectation [3]. Stroet, Opdenakker and Minnaert show need-supportive was distinguished 
into three dimensions: autonomy support (support student's need for autonomy); structure (support students' need for competence); involvement (supports students' need for relatedness) [24]. During their research, in order to measure intrinsic motivation, students used student questionnaires. As a result, the relationship between three dimensions on need-supportive teaching is positively associated with intrinsic motivation (not for involvement). Most of the research just pointed out that teacher expectation is positively associated with students' intrinsic motivation, but the research of Hornstra combined the past researchers' results with need-supportive teaching and students' motivation and refined that teacher expectations were positively but moderately associated with students' intrinsic motivation [25].

Different age of students has different awareness of teacher expectations. In a sample of 579 children and teachers in 30 grade1 (6-7 years old), grade 3 (8-9 years old), and grade 5 (10-11 years old), assessed in fall, younger children were less accurate than fifth-grade students in predicting teacher expectations. Yet, first graders identified teacher treatment to different academic achievers. And fifth students appeared more likely than younger children to reflect teacher expectation when they did self-descriptions, no matter the degree of differential treatment reported in the classroom environment [26].

Table 1: Gender differences in how teachers praise and criticize students [27].

\begin{tabular}{|c|c|c|}
\hline $\begin{array}{l}\text { Types of } \\
\text { response } \\
\text { from } \\
\text { teacher }\end{array}$ & Boys & Girls \\
\hline Praises & Correct knowledge & $\begin{array}{l}\text { "Good"or } \\
\text { compliant } \\
\text { behaviour }\end{array}$ \\
\hline $\begin{array}{l}\text { Overlook } \\
\text { or } \\
\text { ignores } \\
\text { criticizes }\end{array}$ & $\begin{array}{l}\text { "Good"or compliant } \\
\text { behaviour; incorrect } \\
\text { knowledge } \\
\text { Misbehaviour }\end{array}$ & $\begin{array}{l}\text { Misbehaviour; } \\
\text { correct } \\
\text { knowledge } \\
\text { Incorrect } \\
\text { knowledge }\end{array}$ \\
\hline
\end{tabular}

\subsection{How teachers' expectation effect students' intrinsic motivation}

After proposing the Pygmalion effect [1], Good and Brophu modified the effect and designed the teacher expectation process model (Figure 1). Many researchers analysed teacher expectation on the basis of Roenthal's four-factor model, and Many studies have confirmed the relationship between teachers' expectations and differential teacher behaviours. The most representative is Rosenthal's four-element model. Firstly, on classroom atmosphere, teachers will create a more relaxed and dear Classroom atmosphere by Verbal and non-verbal approaches for high expected students. Secondly, on teaching feedback: teachers would provide more amount and positive teaching feedback to highly expected students than low expected students. Thirdly, on the aspect of teaching input, teachers will give them more rich learning materials on the learning situation of high expected students. Last, on the aspect of classroom output: teachers would give more opportunities to high expect students [8].

The perceived teacher expectation influence students' achievement, motivation and academic performance by a series of psychological mediation. As the expected value theory, incentive power $=$ expected value*valence [28], if students think they can succeed on the task, they will have a sense of control on academic. Students' sense of control over academic achievement can be research on three sides: self-concept, attribution and self-efficacy. Self-concept refers to the feelings, attitudes, and evaluations of one's own behaviour, ability, value, etc. On the teaching experiment of Rosenthal, the central expectation effect is students improve and correct self-conception. The teacher is the authority status of the teacher-student relationship, and it definitely affects the students' perception of themselves and their evaluation system. Therefore, students who get teachers' recognition are prone to build more positive and active study behaviours. Attribution refers to the individual's perception or inference of the cause of the actions of oneself or others. Affected by teachers' behaviours, high expected students would contribute a correct attribution method. They are prone to attributing success to their own effort and ability and failing to do not work hard enough. For low expected students, although teachers did not point out they cannot access success, they may decrease the request to expect students low and show sympathy to their mistakes. This will cause the wrong attribution to those students. They cannot master the study process, and these students may think they cannot control the success or failure of their studies. They may give up making an effort, and the next failure just makes them repeat the negative attribution process and cause a vicious circle. Self-efficacy refers to the individual's confidence and belief that he can successfully complete a task. Teachers' present expectations can increase and decrease students' study beliefs. When teachers think students have the potential ability to study, and they will have a positive attitude and enthusiasm devote to teaching. This will potentially improve students' self-belief; meanwhile, in this process, teachers will give students who have high expectations more opportunities and concentration. The more successful experience they have, the more self-belief they will contribute [8]. 


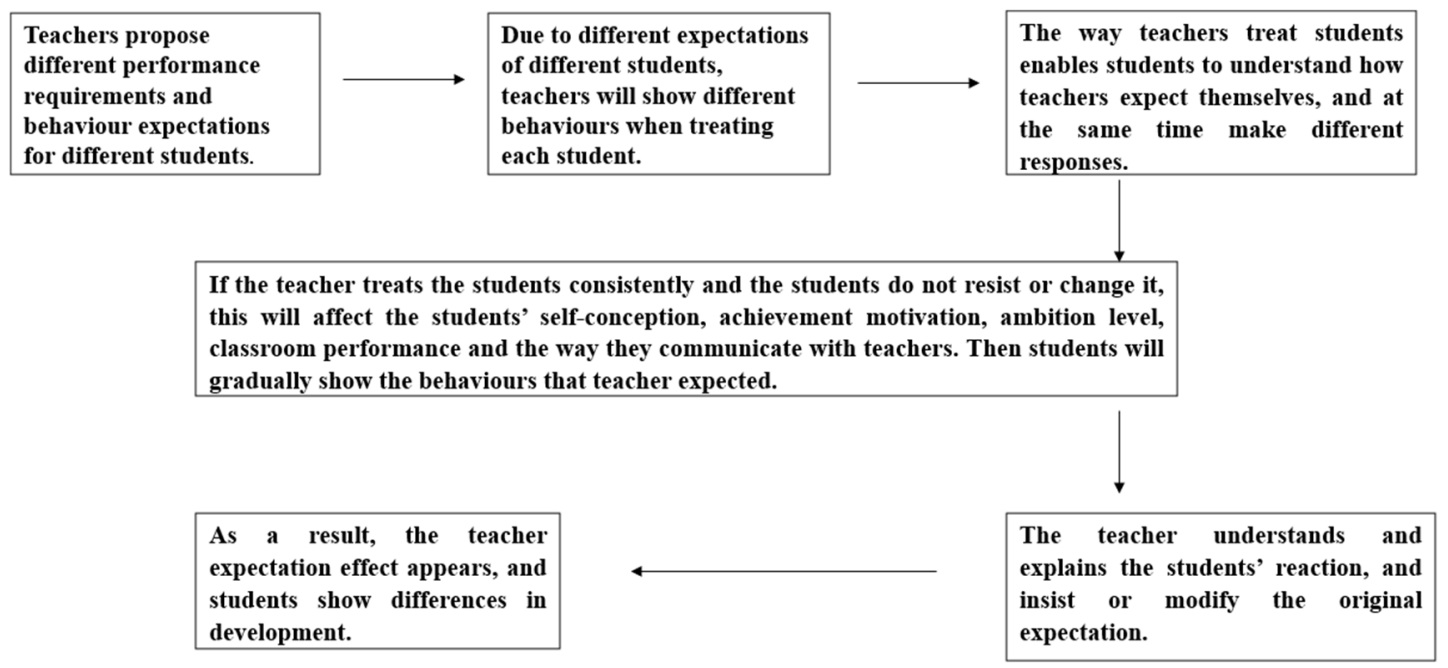

Figure 1 Teacher expectation process model [26].

\section{LIMITATIONS AND DIRECTIONS FOR FUTURE RESEARCH}

Several limitations of research should be noted. Firstly, the research about the effect of teacher expectation on different age students still does not have a systematic conclusion. And for further study, this should be concluded for the deeper research of teacher expectation. There are also other differences like family background, EQ, and so on that can be specifically researched. Secondly, teachers expectations of different genders on different aspects, and because of the gender roles, teachers will give different praise and criticism to different-sex students (Figure 1). However, most of the research didn't measure teacher expectations on different gender. The intrinsic motivation will not be the same. Thirdly, there should be more flexible ways to observe teacher expectation. Most of the research observes teacher expectations mainly by Rosenthal's four-factor model and Cooper's division of teacher expectations into three categories. Teacher nonverbal behaviour can be shown in more ways, not only on academic performance but also on school communication and assessment. Also, it is hard to avoid conflicts on teacher expectations (e.g., some teachers' verbal and nonverbal behaviours may show a different tendency of teacher expectation). Fourth, although there were much research on teacher expectations effect on students' intrinsic motivation, researchers still need to consider some special students in class, like disabled students and different races' students. Fifth, school restrictions such as management or policy guidelines make it difficult to get gains with a randomized control trial. Working with many teachers across multiple classrooms make it hard to measure the fidelity of the intervention [7]. Not much past research in China-controlled student baseline data showed positive associations between teacher expectations and students' future achievement, so it is still unknown whether past teachers can estimate later students' academic achievement progress within the Chinese junior high school context [29].

Future research can investigate dialogue and reciprocal relationships regarding teacher goals, teacher behaviour, and student motivation. In particular, research can help insight into the direction of the relationship [17]. On the basis of the current development of technology and the eruption of COVID-19, online teaching has been a tendency in the future. Therefore, the research about students' online teaching intrinsic motivation and the analysis of persistence and rewards in educational games should intensify research [10]. However, there are also have multiple factors that would influence students' intrinsic motivation. Therefore, there still need huge experiments on motivation.

\section{CONCLUSION}

This paper talked about the effect of perceived teachers' expectations on students' intrinsic motivation. As a result, teacher expectations have a positive but moderate association with students' intrinsic motivation because teacher expectations lead teachers to treat higher- and lower-expectancy students differently. Students will revise achievement expectations and subsequently perform themselves on the basis of their perceived teacher expectations. The way of teacher expectation effect students' intrinsic motivation mainly by Good and Brophu's teacher expectation process model, and some researchers explore it based on Rosenthal's four-factor model. Also, teacher expectation can affect students' intrinsic motivation by a series of psychological mediation. On the basis of the expected value theory, incentive power $=$ expected value * valence. For example, students think they can be successful on the task. Then they will have the control sense on academics. The research can give research 
some directions on the research of teacher expectation and students' intrinsic motivation. Some remained barriers of the researches should be explored in the future. Also, teachers can know the effect of their expectation on students in this essay. They may justify their attitude and take the concern to their nonverbal behaviours to students. This research may attract the interest of some educators and researchers' interest in educational psychology, and some teachers may change their teacher methods by this paper. There should be more research on the systematic research of teacher expectation effect on different age and gender students' academic performance in the future. Also, on the background of the developing distance education, researchers were also able to explore whether students' intrinsic motivation changed because of online teaching.

\section{REFERENCES}

[1] Rosenthal, R., \& Jacobson, L. (1968). Pygmalion in the classroom. The Urban Review, 3(1), 16-20. doi:10.1007/bf02322211

[2] Hoge, R. D. (1984). The Definition and Measurement of Teacher Expectations: Problems and Prospects. Canadian Journal of Education / Revue Canadienne de L'éducation, 9(2), 213. doi: $10.2307 / 1494604$

[3] Brattesani, K. A., Weinstein, R. S., \& Marshall, H. H. (1984). Student perceptions of differential teacher treatment as moderators of teacher expectation effects. Journal of Educational Psychology, 76(2), 236-247. doi:10.1037/0022-0663.76.2.236

[4] West, C. K., \& Anderson, T. H. (1976). The Question of Preponderant Causation in Teacher Expectancy Research. Review of Educational Research, 46(4), 613-630. doi:10.3102/00346543046004613

[5] Kerman, S. (1981). Teacher Expectations and Student Achievement. The Phi Delta Kappan. Retrieved 2016, from http://www.jstor.org/stable/20386148.

[6] Chang, J. (2011). A Case Study of the "Pygmalion Effect": Teacher Expectations and Student Achievement. International Education Studies, 4(1). doi:10.5539/ies.v4n1p198

[7] Rubie-Davies, C. M., Peterson, E. R., Sibley, C. G., \& Rosenthal, R. (2015). A teacher expectation intervention: Modelling the practices of high expectation teachers. Contemporary Educational Psychology, 40, 72-85. doi:10.1016/j.cedpsych.2014.03.003

[8] Ning Feng (2016). On teacher expectancy effect and its application in classroom instruction. Journal of Xinyang college of Agriculture and Forestry. 26(1), 134-136.

[9] Gentrup, S., Lorenz, G., Kristen, C., \& Kogan, I. (2020). Self-fulfilling prophecies in the classroom: Teacher expectations, teacher feedback and student achievement. Learning and Instruction, 66, 101296. doi:10.1016/j.learninstruc.2019.1012

[10] María. Zapata-Cáceres and E. Martín-Barroso, "Applying Game Learning Analytics to a Voluntary Video Game: Intrinsic Motivation, Persistence, and Rewards in Learning to Program at an Early Age," in IEEE Access, vol. 9, pp. 123588-123602, 2021, doi: 10.1109/ACCESS.2021.3110475.

[11] Brophy, J. E., \& Good, T. L. Teacher-student relationships: Causes and consequences. New York: Holt, Rinehart \& Winston, 1974.

[12] Cooper, H. M. (1984). Teacher Expectation Research: A Review with Implications for Classroom Instruction. The Elementary School Journal, 85(1), 77-89. doi:10.1086/461393

[13] Hankins, B. L. (1975). Comparative analyses of teacher verbal and nonverbal behaviour in a traditional and an open-space setting. Digital Commons@ East Tennessee State University. Retrieved September 23, 2021, from https://dc.etsu.edu/etd/2852/.

[14] Asghar Chaudhry, N., \& Arif, M. (2012). Teachers' Nonverbal Behaviour and Its Impact on Student Achievement. International Education Studies, 5(4). doi:10.5539/ies.v5n4p56

[15] Haiyan Zheng \& Minqiang Zhang. (2008). Developing Teacher-Expectancy Consciousness Scale for Middle School Students. Psychological development and education(03) ),113-118. doi:CNKI:SUN:XLFZ.0.2008-03-020.

[16] Lihong Liu \& Qingru Yao. (1996). The influence of teacher expectation on students' academic performance. Psychological Science (06),doi:10.16719/j.cnki.1671-6981.1996.06.007.

[17] Hornstra, L., Stroet, K., van Eijden, E., Goudsblom, J., \& Roskamp, C. (2018). Teacher expectation effects on need-supportive teaching, student motivation, and engagement: a self-determination perspective. Educational Research and Evaluation, 24(3-5), 324-345. doi:10.1080/13803611.2018.1550841

[18] Fan, D. S. (1980). The effects of teachers' expectation on students' grades of mathematics and deportment. Bulletin of Educational Psychology. 
[19] Siregar, N. D., Prasetyawati, W., \& Sary, M. P. (2018, January). Association of Anxiety and Teacher Expectation among High School Students in Jakarta. In Universitas Indonesia International Psychology Symposium for Undergraduate Research (UIPSUR 2017) (pp. 277-283). Atlantis Press.

[20] Ryan, R. M., \& Deci, E. L. (2000). Intrinsic and Extrinsic Motivations: Classic Definitions and New Directions. Contemporary Educational Psychology, 25(1), 54-67. doi:10.1006/ceps.1999.1020

[21] Lepper, M., Corpus, J., \& Iyengar, S. (2005). Intrinsic and extrinsic motivational orientations in the classroom: Age differences and academic correlates. Journal of Educational Psychology, 97, 184-196.

[22] Niehaus, K., Rudasill, K. M., \& Adelson, J. L. (2011). Self-Efficacy, Intrinsic Motivation, and Academic Outcomes Among Latino Middle School Students Participating in an After-School Program. Hispanic Journal of Behavioural Sciences, 34(1), 118-136. doi:10.1177/0739986311424275

[23] Fırat, M., Kılınç, H., \& Yüzer, T. V. (2017). Level of intrinsic motivation of distance education students in e-learning environments. Journal of Computer Assisted Learning, 34(1), 63-70. doi:10.1111/jcal.12214

[24] Stroet, K., Opdenakker, M.-C., \& Minnaert, A.
(2013). Effects of need supportive teaching on early adolescents' motivation: A review of the literature. Educational Research Review, 9, 65-87. doi:10.1016/ j.edurev.2012.11.003

[25] Hornstra, L., Stroet, K., van Eijden, E., Goudsblom, J., \& Roskamp, C. (2018). Teacher expectation effects on need-supportive teaching, student motivation, and engagement: a self-determination perspective. Educational Research and Evaluation, 24(3-5), 324-345. doi:10.1080/13803611.2018.1550841

[26] Weinstein, R. S., Marshall, H. H., Sharp, L., \& Botkin, M. (1987). Pygmalion and the Student: Age and Classroom Differences in Children's Awareness of Teacher Expectations. Child Development, 58(4), 1079. doi:10.2307/1130548

[27] Seifert, K., \& Sutton, R. (2019). Student diversity. Educational Psychology

[28] Midgley, C. (1983). Expectancies, values, and academic behaviours. JT Spence.

[29] Wang, S., Meissel, K., \& Rubie-Davies, C. M. (2021). Teacher expectation effects in Chinese junior high schools: Exploring links between teacher expectations and student achievement using a hierarchical linear modelling approach. Social Psychology of Education. doi:10.1007/s11218-021-09654 